\title{
ALEIRODÍDEOS EM PLANTAS CITRICAS NO ESTADO DE SÃO PAULO, BRASIL (HOMOPTERA, ALEYRODIDAE)
}

\author{
PAULO CESAR RODRIGUES CASSINO
}

ORIENTADOR: EVONEO BERTI FILHO

DISSERTAGAO APRESENTADA A ESGOLA

SUPERIOR OE AGRIEULTURA "LUIZ DE

OUEIROI". DA UNIVERSIDADE OE SÁO

PAULO, PARA OBTENGSAO DO TITULO

DE MESTRE EM ENTOMOLOGIA.

PIRACICABA

ESTADO DE SÃO PAULO - BRASIL

SETEMBRO DE $197 ?$ 
A Cristo, nosso mestre. 
Aos meus dedicados pais, à minha amiga e esposa Suely, $e$ às minhas filhas Suzy $e$ Martha

\section{Dedico}




\section{AGRADECIMENTOS}

Ao Prof. Adriano Lúcio Peracchi, pelo apoio, incentivo e compreensão com que auxiliou a execução e apres entação desse trabalho.

Ao Prof. Evoneo Berti Filho, pela orientação .e liberdade oferecida, não só na parte técnica-científica, mas moral e espiritualmente.

Ao Prof. Cincinato Rory Gonçalves, meu estimado mes tre.

Ao Prof. Eugênio Izecksohn pela colaboraçẫo prestada.

Ao companheiro e colega Prof. Aurino Florencio de Lima, pelo estímulo, dedicação e sugestões.

Ao Prof. e colega Fernando Zanotta da Cruz, pelos ensinamentos, auxílio nas montagens e revisões preliminares.

Aos Professores e colegas do setor de Entomologia do CENA, pela acolhida e apoio que sempre encontrei naquele setor.

Aos demais colegas do curso e em especial aos amigos Ricardo Sgrillo, Deosdedes Barcellos e Antônio O. Roccia.

Ao Chefe do Departamento de Entomologia da ESALQ, 
Prof. Dr. Domingos Gallo, aos professores e aos funcionários daquele Departamento.

Ao colega e amigo Engo Agro Francisco Racca Filho, pelas revisões realizadas.

Aos parentes, amigos e colegas que influiram direta $e$ indiretamente para que hoje eu pudesse realizar este trabalho, destacando a pres ença decisiva do estimado amigo Sr. T.R.A. .

Aos acadêmicos, Francisco Mendes pelas fotografias $e$ Maria Teresa da Cruz Oliveira pela realização dos desenhos.

Ao CNPq por ter concedido bolsa de estudos no início de nosso curso.

Ao PICD/PEAS/UFRRJ, a Coordenadora e assessores, pela bolsa concedida, no momento crucial de nosso curso. 
INDICE

Página

RESUMO.............................. 1

INTRODUÇAO .............................

REVISAO DE LITERATURA ............... 4

MATERLAL E METODOS................... 8

RESULTADOS .............. 11

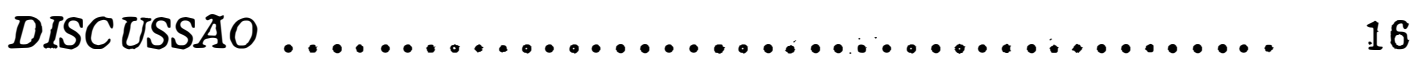

CONCLUSOES ............................ 18

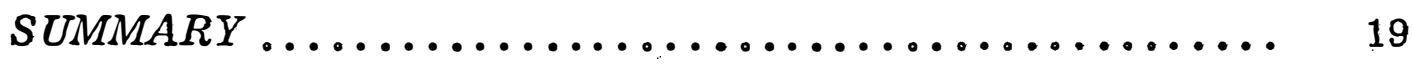

LITERATURA CITADA ................... 21

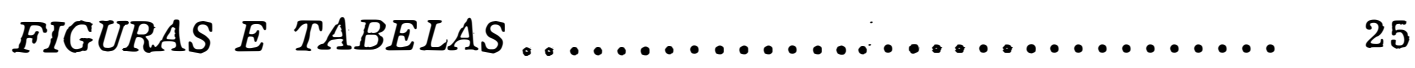

PRANCHAS E MAPA ..................... 34 


\section{RESUMO}

Ao ser realizado um estudo sobre Aleurothrixus floccosus (Maskell, 1896), em Piracicaba, Estado de São Paulo, verificou-se também a ocorrência de outras espécies de aleirodídeos em plantas cítricas, destacando-se Dialeurodes citrifolii Morgan, 1893) e Paraleyrodes bondari Peracchi, 1971.

A partir desta observação foi realizado um breve estudo morfológico das espécies mais frequentes, bem como um levantamento da ocorrência desses insetos em algumas regiões livres para citricultura nesse Estado.

O material estudado foi montado em lâminas e foram confeccionadas fotografias que permitiram o reconhecimento das espécies no campo.

Em cada pomar visitado foram escolhidas amostras, for madas por 10 árvores ao acaso, sendo observada em cada planta, a ocor rência de aleirodídeos.

O levantamento totalizou 92 amostras, coletadas em 31 municipios, perfazendo um total de 920 plantas cítricas, das quais 5,97\% (55 árvores) se apresentaram com A. floccosus, 12, $82 \%$ (118 árvores)can P. bondari e 87,50\% (805 árvores) com $\underline{D}$. citrifolii. Nos 31 municípios visitados verificou-se a ocorrência de $A$. floccosus em 20 (64,51\%), de 
P. bondari em 25 (80,64\%) e D. citrifolii em 31 (100\%).

Pelo levantamento realizado, concluiu-se que cinco es pécies de aleirodídeos foram encontradas associadas a plantas cítricas no Estado de São Paulo: Dialeurodes citrifolii Morgan, 1893); Paraleyrodes bondari, Peracchi, 1971; Aleurothrixus floccosus (Maskell, 1896); Paraleyrodes crateraformans Bondar, 1923 e Aleurotrachelus sp., sendo que as duas primeiras apresentaram maior índice de ocorrência, en-

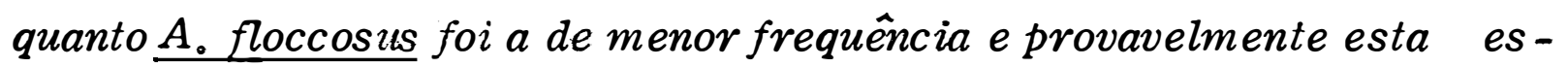
pécie vem sendo confundida com outras da mesma família. 


\section{INTRODUÇAO}

Entre os numerosos insetos associados a plantas cítricas, incluem-se algumas espécies de aleirodídeos (Hom., Aleyrodidae).

Conforme citações da literatura, a espéciè encontrada associada à Citrus, com mais frequência, é Aleurothrixus floccosus (Mas kell, 1896). Entretanto, em abril de 1975, executando um estudo preliminar sobre o referido inseto, a fim de observar a flutuação populacional do mesmo, no pomar do Departamento de Entomologia da Escola Superior de Agricultura "Luiz de Queiroz", o autor verificou que além deste, ocorriam outros aleirodídeos, destacando-se com mais frequência Dialeurodes citrifolii (Morgan, 1893) e Paraleyrodes bondari Peracchi, 1971.

Quanto à importância dos aleirodídeos em Citrus, TALHOUK (1975) considera que no Brasil, A. floccosus apresenta menor im portância econômica que $\underline{D}$. citrifolii.

Considerando esses fatos, o autor se propôs apresentar um breve estudo morfológico diferencial entre as espécies de maior frequência no referido pomar e em seguida realizar um levantamento da pro vável ocorrência desses insetos nos pomares de regiões livres para citricultura no Estado de São Paulo. 


\section{REVISAO DE LITERATURA}

HEMPEL (1904) observou a presença de Aleyrodes horridus Hempel, 1899, associado a laranjeiras, em Campinas, SP $e$ redescreveu esta espécie juntament? com seu principal inimigo natural, Eretmocerus paulistus (Hym., Aphelinidae).

QUAINTANCE e BAKER (1913) apresentaram um estudo sobre a classificação da familía Aleyrodidae, dividindo-a em Udamoselinae, Aleyrodinae e Aleurodicinae, comentando a possivel origem dos aleirodídeos. Nesse trabalho foram descritos vários gêneros e espécies novas para a ciência.

Dando continuidade ao trabalho anterior, QUAINTANCE e BAKER (1914) descrevem outros gêneros e espécies.

QUAINTANCE e BAKER (1917) realizaram uma revisão da família Aleyrodidae, descrevendo novos gêneros e espécies, redescrevendo outras e apresentando uma série de pranchas das diversas espécies de aleirodídeos.

Segundo BONDAR (1923), os aleirodídeos são bem representados entre nós e nesse trabalho o autor descreveu nove gêneros $e$ cinquenta e quatro espécies, fazendo ainda redescrições e comentários so bre a ocorrência de $\underline{A}$. floccosus em laranjeiras e tangerineiras, na 
Bahia.

COSTA LIMA (1928) fez um estudo sobre Aleurodicinae, no qual descreveu cinco espécies novas para ciência e apres entou considerações à respeito de outras formas da referida sub-família.

Complementando seu trabalho anterior, BONDAR (1928), acrescentou mais quinze espécies novas, associadas a diversas plantas.

FONSECA e AUTUORI (1932) ao apresentarem uma lis ta dos insetos que atacam plantas cítricas no Brasil, incluem entre os aleirodídeos: Hexaleurodicus jaciae Bondar, 1923, observado em folhas de Citrus na Bahia; Paraleyrodes singularis Bondar, 1923, em laranjeiras e em outras plantas, na Bahia; Dialeurodes (Gigaleurodes)struthanthi (Hempel, 1901) encontrado sobre laranjeiras na Paraíba e São Paulo e, finalmente $A$. floccosus, sem indicação de ocorrência.

Ainda FONSECA (1934) ao relacionar as principais pragas observadas em plantas de maior cultivo no Estado de São Paulo, no

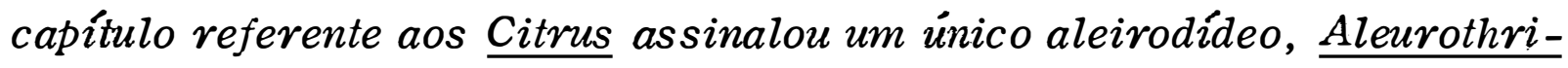
xus floccosus, afirmando que o referido ins eto era muito comum nos laranjais do Estado, sendo parasitado pelos microhimenópteros: Eretmocerus paulistus Hempel, 1904, Prospaltella brasiliensis Hempel, 1904)e Signifora townsendi Ashmead, 1900.

Posteriormente, FONSECA (1936) informou que $\underline{A}$. floc cosus é a espécie mais comum entre nós, sendo muito nocivo às plantas do gênero Citrus, estando disseminada por todo país e fez uma rápida des crição do pupário e comentários sobre a sua biologia, prescrevendo ainda métodos de combate.

Segundo COSTA LIMA (1942a), o genero Aleurothrixus Quaintance e Baker, 1914, compreende os sub-gêneros, Philodamus, res trito à California, E.U.A. e Aleurothrixus, onde incluiu cinco novas es- 
pécies.

GALLO e FLECHTMANN (1962) ao apresentarem as pragas mais importantes das grandes culturas, referiram-se a $A$. flocco-

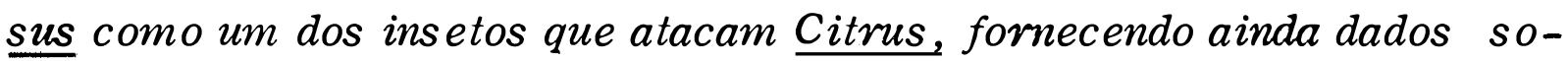
bre sua biologia.

De acordo com SILVA et alii (1968) há outros aleirodí-

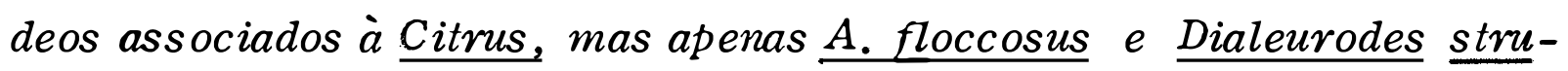
thanthi ocorrendo em São Paulo.

GALLO et alii (1970) no capítulo referente as pragas dos $\underline{\text { Citrus, }}$ citam $\underline{A}$. floccosus, apresentando dados sobre a sua biologia, reconhecimento e controle.

PERACCHI (1971) referindo-se a dois aleirodídeos pragas dos Citrus no Estado do Rio de Janeiro, descreveu uma espécie nova, Paraleyrodes bondari e redescreveu Dialeurodes citrifolii, assinalando pela 1a. vez a sua ocorrência no Brasil.

CASSINO (1975) assinalou a presença de $\underline{D \text {. citrifolii }} e$ P. bondari pela 1a. vez no Estado de São Paulo, nos municípios de Piracicaba e Cordeirópolis, em limão taiti e em laranjeira.

De acordo com TALHOUK (1975), em uma lista das pra gas de Citrus em todo mundo, elas são classificadas em 3 categorias: de maior importância, com importância e de menor importância econônica. Entre os aleirodídeos, o autor assinalou para o Brasil, A. floccosus ccmo de menor importância e $\underline{D}$. citrifolii como praga de importância econômica.

MARICONI (1976) referindo-se às pragas dos $\underline{\text { Citrus, in }}$ formou que entre outras, os aleirodídeos $A$. floccosus $e \underline{D \text {. citrifolii são }}$ pragas dessa cultura sendo o segundo de maior importância que o prime $\underline{i}$ 
ro. Nesse trabalho o autor afirmou que o $\underline{D}$. citrifolii foi confundidb com $o$. A. floccosus em seus trabalhos anteriores. 


\section{MATERIAL E METODOS}

O presente trabalho foi realizado com o exame de material colecionado no campo, de onde as folhas com exemplares foram transportadas em sacos de papel para o laboratório. Os aleirodídeos foram retirados das folhas sob binocular, com auxilio de estiletes $e$ montados em lâminas, conforme métodos preconizados, respectivamente, por COSTA LIMA (1942 b) e BAKER e WHARTON (1952).

No 19 caso, o material foi colocado em hidróxido de potássio à 10\%, em cápsula de porcelana e aquecido em banho maria, até a fervura. Com auxílio de tiras de papel, os exemplares foram transferidos para uma gota de fenol colocada no centro de uma lâmina. Utilizando se um fragmento de lamínula, o material foi comprimido com a finalidade de esvaziar o seu conteúdo. Es ta última operação foi repetida 2 ou 3 vezes visando a desidratação do mesmo. Em seguida foi colocada sobre o material, uma gota de corante (fucsina de Ziehl) e a lâmina levada à chama de lâmpada de álcool, aquecendo-se até o despreendimento de vapores. O excesso de corante foi retivudo com auxitio de papel de filtro, colocando-se então uma gota de fenol para que se procedesse a diferenciação. Após a passagem do material em fenol-xilol (fenol, 75\% e xilol, 25\%) em xilol-fenol (xilol, $75 \%$ e fenol, $25 \%$ e em xilol puro, o mesmo foi montado em bálsamo do Canadá, incluido entre lâmina e lamínula.

Quanto ao método de BAKER e WHARTON (1952), o ma- 
terial foi montado em líquido de Hoyer, entre lâmina e lamínula e levado $\grave{a}$ estufa, onde foi mantido à $45^{\circ} \mathrm{C}$ por três dias, para clarificação.

o primeiro método foi utilizado para as formas mais esclerosadas ou escuras, enquanto o segundo, foi empregado para montagem de formas jovens e pupários hialinos.

$O$ material foi es tudado em microscópio de contraste de fase WILD M-20 e os desenhos foram feitos com auxílio de câmara clara acoplada ao referido aparelho.

Algumas fotografias foram feitas, a fim de permitir o reconhecimento no campo, das espécies em estudo.

Com o objetivo de realizar um levantamento da ncorrên cia das espécies de aleirodídeos em estudo, foi planejado um programade visitas a pomares de algumas regiões livres para o plantio de Citrus no Es tado de São Paulo. Para tanto foram consideradas como regiões livres para o plantio de Citrus, aquelas onde não ocorrem o cancro cítrico $e$ a tristeza de Capão Bonito, doenças consideradas limitantes para a citricultura, respectivamente pela Comissão Técnica Permanente da Citricultura (1973) e MULLER e COSTA (1971). (Mapa anexo)

As viagens foram realizadas através das principais vias de acesso rodoviário, que cortam as respectivas regióes, durante o período de abril a junho de 1976 e dentre elas destacam-se como fundamentais:

1 - Em abril de 1976, Piracicaba-Igarapava

2-Em abril de 1976, Piracicaba-Piraçunanga

3 - Em maio de 1976, Piracicaba-Columbia

4-Em maio de 1976, Piracicaba-Barretos. 
Os municípios circunvizinhos a Piracicaba, foram visitados nos intervalos das viagens mais longas. Durante uma viagem ao Rio de Janeiro em abril de 1976, foram visitados vários municípios ao longo da Rodovia Presidente Dutra.

$A$ ocorrência dos aleirodídeos estudados foi registrada nos diversos pomares visitados, através amostragem representada por dez árvores, escolhidas ao acaso. Várias amostras foram repetidas em alguns municípios, dependendo da sua localização, produtividade e extensão do pomar visitado.

Cada árvore foi obs ervada durante determinado tempo, enquanto o autor se deslocava em torno da mesma, registrando em ficha própria a ocorrência dos insetos. Para tanto, observava-se a ocorrência de adultos e, em caso positivo, identificava-se a espécie, através do pupário.

Após as viagens, e a partir dos dados obtidos nas respectivas amostragens, foi organizada uma tabela, relacionando os municípios visitados, o nímero de árvores observadas e a ocorrência de aleirodídeos nessas plantas cítricas.

Os dados obtidos foram transformados em percentagem dispensando-se qualquer análise estatís tica. 


\section{RESULTADOS}

No decorrer dos estudos realizados foram encontradas as seguintes espécies de aleirodídeos, em plantas cítricas no Estado de São Paulo :

Aleurodicinae

a. Paraleyrodes bondari Peracchi, 1971

b. Paraleyrodes crateraformans Bondar, 1923

Aleyrodinae

c. Aleurothrixus floccosus (Maskell, 1896)

d. Aleurotrachelus sp.

e. Dialeurodes citrifolii Morgan, 1893)

Das espécies enumeradas, P. bondari, A. floccosus $e$ $\underline{\text { D. citrifolii, }}$ destacaram-se pela maior frequência com que foram encon tradas.

Visando possibilitar a identificação dessas espécies, se gue-se uma sucinta diagnose diferencial, baseada nos caracteres do ovo e do pupário, bem como a sinonímia e principais citações taxonômicas re ferentes a cada uma delas. 
Aleurothrixus floccosus (Maskell, 1896)

(Prancha II e Fig. 1 e 2)

Aleurodes flocosa Maskell, $1896: 432$

Aleurodes horridus Hempel, 1899: 394

Aleyrodes howardi Quaintance, 1907

Aleurothrixus howardi Quaintance e Baker, $1916: 466$

Aleurothrixus (Aleurothrixus) floccosus (Maskell, 1896): Quaintance e Baker, 1917:403

Aleurothrixus floccosus (Maskell, 1896): Bondar, $1923: 165$

Aleurothrixus floccosus (Maskell, 1896): Costa Lima, $1942: 425$

Ovo - Eliṕtico, provido de um pedúnculo curto. Branco leitoso logo após a oviposição, tornando-se amarelo e até castanho, de acordo com o desenvolvimento; encontrados sobre as folhas, dispostos em círculos de 2,5 a $3 \mathrm{~mm}$ de diâmetro.

(Prancha II.A)

Pupário - Sub-elíptico, de cor amarela até castanho escuro. Região sub-marginal com 18 pares de poros simples. Disco dorsal com suturas dos segmentos bem pronunciadas. O tórax é separado do abdônen por uma fenda transversal conspícua, perto da qual há um par de fortes cerdas; um par de pequenas cerdas mais longas, um lateral e outro na parte caudal. Orifício vasiforme sub-circular, pequeno, com a margem lisa; opérculo hemisférico, a sua margem posterior com entalhes; lingula quas p invisivel, mais cur ta que o opérculo. (Prancha II.C). 
Dialeurodes citrifolii (Morgan, 1893)

(Prancha III e Fig. 3 e 4)

Aleyrodes citrifolii Morgan, $1893: 70$

Aleyrodes nubifera Berger, $1909: 67$

Aleyrodes nubifera: Morril e Baker, $1911: 86$

Dialeurodes citrifolii: Quaintance e Baker, $1914: 97$

Dialeurodes citrifolii: Quaintance e Baker, $1916: 469-470$

Dialeurodes (Dialeurodes) citrifolii: Quaintance e Baker, $1917: 412-415$

Dialeurodes citrifolii: Silvestri, $1927: 18-19$

Dialeurodes citrifolii: Peracchi, $1971: 149$

Ovo - Elíptico, provido de um pedínculo curto, amarelo claro, logo após a postura, tornando-se negro em seguida, recoberto por fina pulverulência cérea branca, que se dispõe em forma de alvéolos. São encontrados dis tribuidos irregularmente nas folhas. (Prancha III.A)

Pupário - Elíptico, amarelo-claro, desprovido de manchas oculares, com margem sutilmente denteada, providas de cerdas antero-marginais curtas e inseridas em tubérculos, apresentando dorsalmente estrias e 15 pares de pequeninas cerdas claviformes; disco dor sal com poros simples e esparsos, dobras traqueais visiveis, principalmente a caudal. (Prancha III. B). Orifício vasiforme sub -circular, com margem denteada; opérculo sub-triangular, com a metade apical recoberta por curta pilosidade, preenchendo qua se todo orifício e cobrindo a língula. (Prancha III.C). 
Paraleyrodes bondari Peracchi, 1971

(Prancha IV e Fig. 5 e 6)

Paraleyrodes bondari: Peracchi, $1971: 149$

Ovo - Elíptico, provido de pedúnculo relativamente longo, amarelo claro, recoberto por finíssima pulverulência cérea branca. (Prancha IV.A)

Pupário - Elíptico, margem denteada com 2 cerdas antero-marginais cur tas e 2 postero-marginais mais des envolvidas; apresentando dorsalmente 14 pares de cerdas, sendo 3 anteriores, 10 laterais e 1 caudal; cerdas cefálicas presentes; disco dorsal com 7 poros com postos, sendo 1 cefálico e 6 abdominais; um par de pequenas cerdas situadas no orifício vasiforme. (Prancha IV.B). Orifício vasiforme sub-triangular, com ápice arredondado, opérculo preenchendo metade do orifício, anguloso dos lados, com margem simuosa; língula saliente, alongada, recoberta por curta pilosidade e dotada de 4 cerdas longas e robustas. (Prancha IV.C).

$E_{m}$ condições de campo, as espécies referidas poderão ser reconhecidas pelos seguintes aspectos:

Aleurothrixus floccosus (Fig. 1 e 2): Pupário pequeno, com aproximadamente $0,8 \mathrm{~mm}$ de comprimento e $0,5 \mathrm{~mm}$ de largura, castanho-escuro, rodeado por abundantes filamentos de cera branca, em forma de flocos. Ocorrem geralmente nas páginas inferiores das folhas, em grupos, podendo formar colônias numerosas, favorecendo assim o aparecimento de fumagina irtensa.

Dialeurodes citrifolii (Fig. 3 e 4): Pupário grande, achatado, apro ximadamente com 1,4 mm de comprimento e 1,0 $\mathrm{mm}$ de lar- 
gura, amarelo esverdeado, desprovido de filamentos de cera. Localizam-se nas páginas inferiores das folhas, isoladamente e quando ocorrem em grande número, favorecem também o aparecimento da fumagina.

Paraleyrodes bondari (Fig. 5 e 6): Pupário pequeno, com 0,9 $\mathrm{mm}$ de comprimento e 0,6 $\mathrm{mm}$ de largura, branco leitoso, apresentando alguns filamentos longos e quebradiços de cera bran$c a$, os quais servem de refúgio para os adultos e camuflagem para os ovos. Ocorrem isoladamente na página inferior das folhas e raramente reunem-se em grupos.

A tabela I, representa o levantamento que abrangeu 92 amostras observadas em 31 municipios.

Na tabela II, constata-se que das 920 plantas cítricas examinadas , 5, $97 \%$ (55 árvores) apresentaram A. floccosus; 12,82\% (118

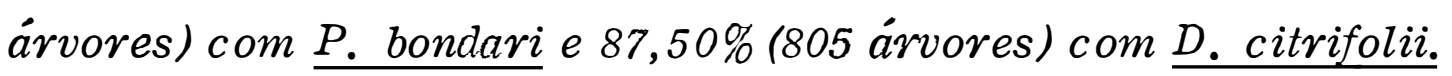

A tabela III, mostra que dos 31 municípios visitados, o A. floccosus foi encontrado em 20 deles (64,51\%), P. bondari em 25 (80,64\%) e oD. citrifolii em 31 (100\%).

As observações de Paraleyrodes crateraformans Bondar, 1923 e Aleurotrachelus sp., constituem a Ia. referência para o Estado de São Paulo, associados à Citrus. 


\section{DISCUSSAO}

Inicialmente tomam-se necessárias algumas considerações sobre a data correta em que foi descrita a espécie de. Maskell (1896). Essa espécie foi descrita como Aleurodes flocosa, com base em material da Jamaica, remetido por Cockrell e encontra-se descrita no Vol. XXVIII do "Transactions and Proceedings of the New Zealand Institute", relativo ao ano de 1895, data essa tomada como referência. Entretanto esse volume foi publicado em junho de 1896, como consta na página de rosto do mesmo. Acresce ainda que a contribuição de Maskell,foi lida na reunião de "Wellington Philosophical Society", realizada em 2.6 de feverciro de 1896, o que confirma ter sido a espécie descrita em 1896 e não 1895, como é comumente citada.

Os dados obtidos contrariam citações anteriores, nas quais a "mosca branca dos citros", A. floccosus, era considerado como única espécie de importância econômica, associada às plantas cítricas.

Analisando as tabelas I, II e III, verifica-se que o $\underline{D}$. citrifolii foi o aleirodídeo de maior frequência entre os estudados $e$ as sim sendo, acredita-se que esta espécie entre outras, tem sido confun-

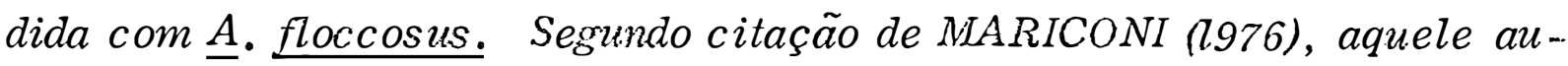
tor admile ter confundido as espécies em quesião, em seus trabalhos anteriores. 
Pode-se aceitar este equívoco, considerando que possivelmente apenas os adultos destes insetos tenham sido observados, quando em se tratando de aleirodídeos, torna-se necessário e indispensável o exame dos pupários.

Outro fato que pode ter influido neste equívoco, referese aos trabalhos publicados sobre aleirodídeos em plantas cítricas, que desde 1904 até 1971, citam e dão ênfase ao A. floccosus, como principal espécie de importância econômica para a citricultura no Brasil.

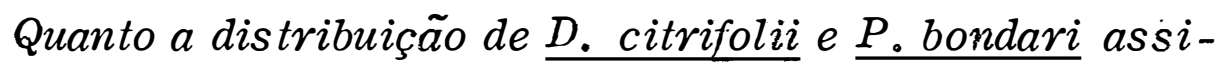
nalados até então para o Estado da Guanabara, hoje Munic ípio do Rio de Janeiro e no Município de Itaguaí, campus da Universidade Federal Rural do Rio de Janeiro, (PERACCHI, 1971) e para São Paulo, Municípios de Piracicaba e Cordeirópolis (CASSINO, 1975), acredita-se na sua ocorrên cia em outras regiões do país, tendo em vista, terem sido estas duas es; pécies observadas pelo autor em Magé, Nova Iouaçu e Itaboraí, municípios citrícolas do Estado do Rio de Janeiro. 


\section{CONCLUSOES}

1. Cinco espécies de aleirodídeos, ao menos, encontram-se associadas a plantas cítricas no Estado de São Paulo.

a. Dialeurodes citrifolii (Morgan, 1893)

b. Paraleyrodes bondari Peracchi, 1971

c. Aleurothrixus floccosus (Masīell, 1896)

d. Paraleyrodes crateraformans Bondar, 1923

e. Aleurotrachelus sp.

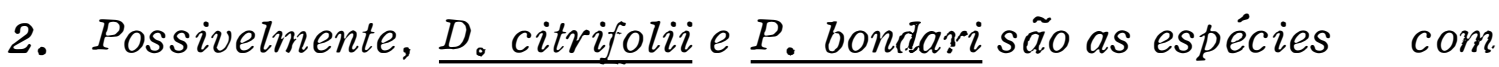
maiores índices de ocorrência em plantas cítricas no Estado de São Paulo, enquanto A. floccosus é aquela de menor ocorrência.

3. Diversas referências na literatura à A. floccosus, infestandoplan tas cítricas, devem ser atribuidas a outras espécies de aleirodídeos, principalmente $\underline{D \text {. citrifolii. }}$

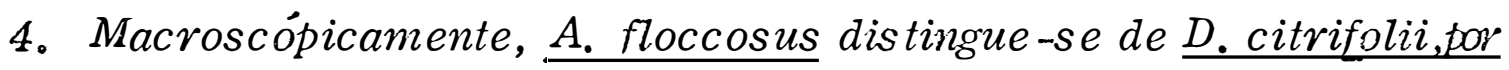
apresentar, aquele, o pupário geralmente castanho-escuro, com abundante secreção cérea branca, enquanto $\underline{D}$. citrifolii tem $o$ pupário amarelo esverdeado, desprovido de secreção cérea. 


\section{SUMMARY}

Among different species of whiteflies damaging citrus trees in Piracicaba, State of São Paulo, Brazil, Dialeurodes citrifolli (Morgan, 1893), Paraleyrodes bondari Peracchi, 1971 e Aleurothrixus floccosus (Maskell, 1896), were the most important pests.

A brief morphological study and a survey of the occurrence of these insects were made in various citricultural areas of the above indicated state. The pupa case were mounted on slides andpictures were taken to use them in identification of different species in the field. Ten trees samples were randonized, from each orchard and the presence of aleirodids were annoted.

The total of samples were 92, including 920 trees, selected from 37 municipios. The results indicated that 55 trees (5.97\%) were attacked by $A$. floccosus, 118 trees $(12,82 \%)$ by $\underline{P \text {. bondari }}$ and 805 trees $(87.50 \%)$ by $\underline{D}$. citrifolii.

In relation with the incidence of the aleirodids in $31 \mathrm{mu}$ nicipios, results showed that in 20 municipios (64.51\%) occurred A. floc-

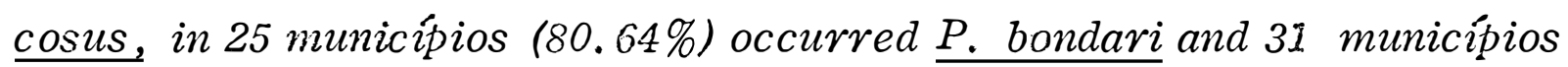
(100\%) occurred D. citrifolii.

Also, the results showed that there are at least two more species of whiteflies Paralevrodes crateraformans Bondar, $1923 e$ 
Aleurotrachelus sp. in the State of São Paulo, damaging citrus trees. 


\section{LITERATURA CITADA}

BAKER, E. W. e G.W.WHARTON, 1952。 An Introduction to $\underline{\text { Acarolo- }}$ gy. McMillan, New York, 465 pp.

BERGER, E. W., 1909. White fly studies in 1908. Bull. Fla. agric. Exp.

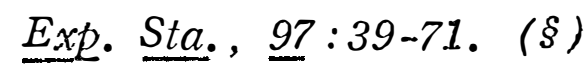

BONDAR, G., 1923. Aleyrodídeos do Brasil. Sec. da Agric. Ind. Obras Públicas. Bahia. Secção de Pathologia Vegetal. 182 pp.

BONDAR, G., 1928. Aleyrodídeos do Brasil. (2a.contribuição)。Sec.de Agric. Ind. Obras Públicas. Bahia. Secção de Pathologia Vegetal。37pp。

CASSINO, P. C. R., 1975. Ocorrência de Dialeurodes citrofolii (Morgan, 1893) e Paraleyrodes bondari Peracchi, 1971 (Hom., Aleyrodidae) em plantas cítricas no Estado de São Paulo. Nota prévia). Resumos do IIIo Congresso Bras. de Fruticultura, Rio de Janeiro, J.F. R.R.J. : 46.

COMISSAO TECNICA PERMANENTE DE CITRICULTURA, 1973. Secret. de Agric.. Inst. Agronômico. Atlas do zoneamento agrícola do Estado de São Paulo. Restrições fitossanitárias temporárias. Vol. 2 , caria 6.3 .4 . 
COSTA LIMLA, A. M. da, 1928. Contribuição ao estudo dos Aleyrodídeos da sub-família Aleurodicinae. Mem. Inst. Osw. Cruz Supl. 4 : $128-140$, 16 figs.

COSTA LIMA, A. M. da, 1942a. Sobre Aleirodídeos do gênero Aleurothrixus (Hom.). Rev. Bras. Biol., Rio de Janeiro, 2 (4):419-426.

COSTA LIMA, A. M. da, 1942b. Insetos do Brasil, 39 Tomo. Homópteros. Escola Nac. Agronomia, Série didática no 4, 327pp.

FONSECA, J. P. e M. AUTUORI, 1932. Lista dos principais insetos que atacam plantas cítricas no Brasil. Rev。Ent. ii(2):202-216.

FONSECA, J. P., 1934. Relação das principais pragas observadas nos anos de 1931, 1932 e 1933, nas plantas de maior cultivo no Estado de São Paulo. Arg. Inst. Biol., S. P. (5): 263-289.

FONSECA, đ. P., 1936. A mosca branca dos citrus. Biológico. 2(8): $285-286$ 。

GALLO, D. e C. H. W. Flechtmann, 1962. As mais importantes pragas das grandes culiuras. Bol. (did.). Esc. Sup. Agric. "L. de Queiroz". (3): 144pp. Piracicaba.

GALLO, D., O. NAKANO, F. M. WIENDL, S. SILVEIRA NETO e R. L. CARVALIO, 1970. Manual de Entomologia. Pragas das Plantas $\underline{e}$ seu controle. São Panio. Ed. Agron. Ceres. 858 pp, 437 figs.

HEMPEL, A. , 1899. Descriptions of the three new species of Alcurodidae from Brazil. Psyche. Camb. Mass. $8(2$ 80):394-395.

HEMPEL, A., 1904. Nolas sobre os dois inimigos da laranjeira. Bol. Agric. S. Paulo : $10-21$. 
MARICONI, F. A. M., 1976. Inseticidas e seu emprego no combate às pragas. Pragas das plantas cultivadas e dos produtos armazenados. Tomo II. S. Paulo, Nobel. 466 pp, 328 figs. (Bibl. Rural)

MASKELL, W. M., 1896. Contributions toward a monograph of the Aleu rodidae, a family of Hem-Hom. Trans. N.Z. Inst. 28:411 449.

MORGAN, H. A., 1893. The orange and other citrus frits, from seed to market, with remedies for the latter. La. Agric. Exp. Spec. Bull. : 110. (\&)

MORRIL, A. W. e E. A. BACK, 1911. White flies injurious to citrus in Florida. Bull. U. S. Bur. Ent. 92:1-109.

MULLER, G. W. e A. S. COSTA, 1971. Tristeza dos citros. Variante Capão Bonito. Bol. Técnico. SCR. No 71. I8pp CATI. S。 Paulo.

PERACCHI, A. L., 1971. Dois aleirodídeos pragas de Citrus no Brasil. (Hom., Aleyrodidae). Arq. Mus. Nac. Rio de Janeiro. 28:145-159.

QUAINTANCE, A. L., 1907. The more import Aleyrodidae infesting eco nomic plants, with descriptions of a new species infesting the orange. Tech. Ser. U. S. Bur. Ent. Washington. 12:89-94.

QUAINTANCE, A. L. e A.C.BAKER, 1913. Classification of the Aleyrodidae. (Part I). Tech.Ser.U.S. Bur.Ent. Washington. 27:1-93.

QUAINTANCE, A. L. e A.C.BAKER, 1914. Classification of the Aleyrodidae. (Part II). Tech. Ser. U. S. Bur. Ent. Washington. 27 : $95-109$.

QUAINTANCE, A.L.e A.C.BAKER, 1916. Aleyrodidae or White flies attacking the orange, with descriplions of three new species 
economics importance. J. Agric. Res. 6 (12):459-472.

QUAINTANCE, A. L. e A.C.BAKER, 1917. A contribuitions to our knowledge of the white flies of the sub-family Aleyrodinae (Aleyrodidae). Proc. $\underline{\text { U. }}$ S. Nat. Mus. $\underline{\text { N1 }}: 335-445$.

SILVA, A. G. d'A., C. R. GONÇALVES, D. M.GALVAO, A. J. L. GONÇALVES, J.GOMES, M. N. SILVA e L. SIMONI, 1968. Quarto catálogo dos insetos que vivem nas plantas do Brasil. Seus parasitos e predadores. Depto de Defesa e Inspeção Agropecuária, Ser. Defesa Sanitária Vegetal, Laboratório Central ae Patologia Vegetal, Ministério da Agric. Rio de Janeiro, Parte II. Tomo 1? 622pp.

SILVESTRI, F., 1927. Contribuzione alla conoscenza digli Aleurodidae (Insecta:Hemiptera) viventi su Citrus in Estremo Oriente e dei loro parassiti. Boll. Lab. Zool. Portici. 21:1-60.

TALHOUK, A.S., 1975. Citrus Pests throughout the world. In: Citrus. Ciba..Geigy Agrochemicals. Technicals monograph. Suiça.4:21-23.

Obs.: Os trabalhos assinalados com (\$) náo foram consultados no original. 
10. FIGURAS E TABELAS 


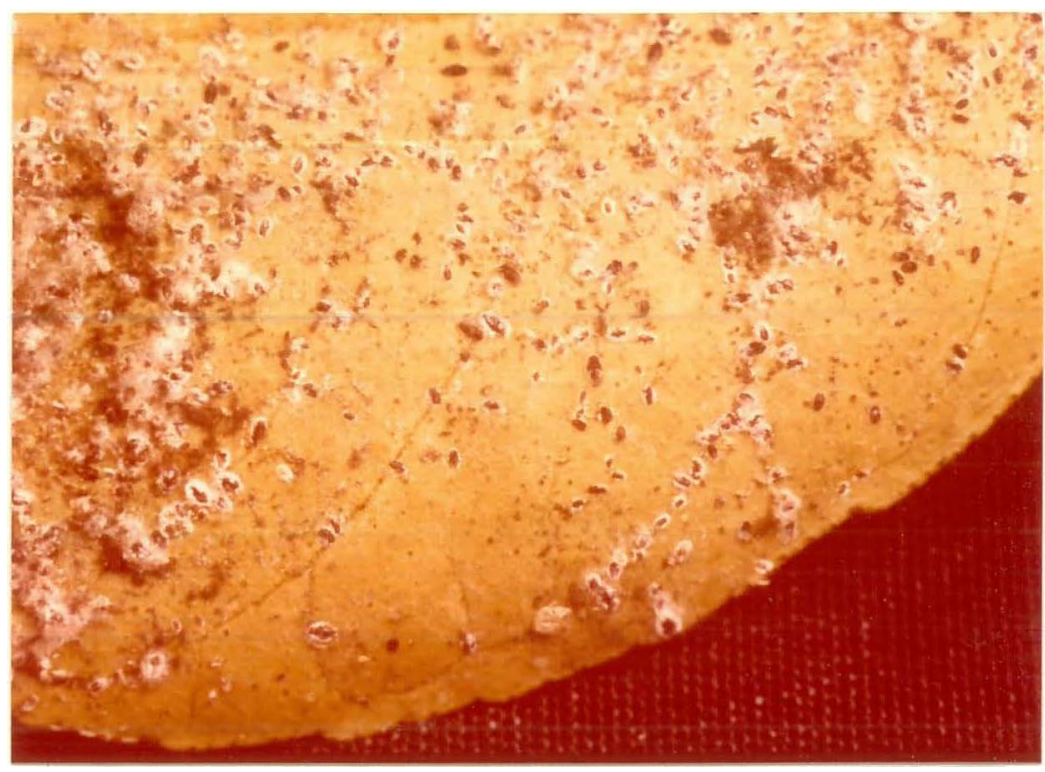

Fig. I

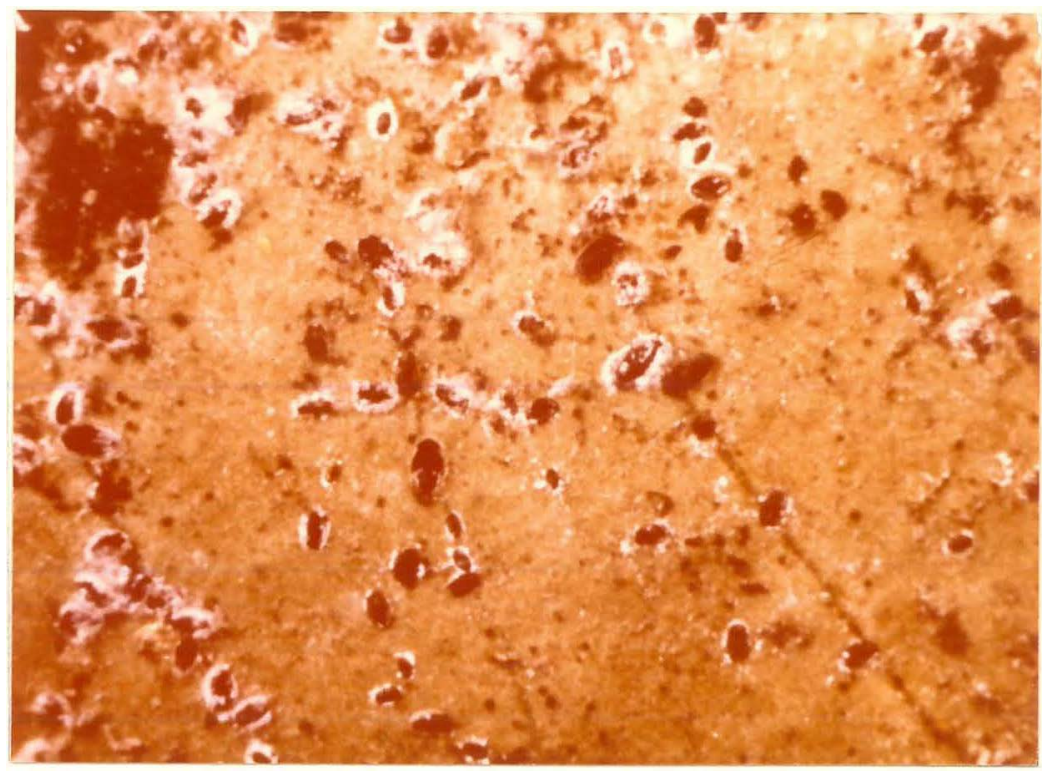

Fig. 2

Alearolhrixus floccosus (Maskell, 1896) sobre folhas de Citrus sp., fig. $7: 4 X$ e fig. $2: 8 X$ 


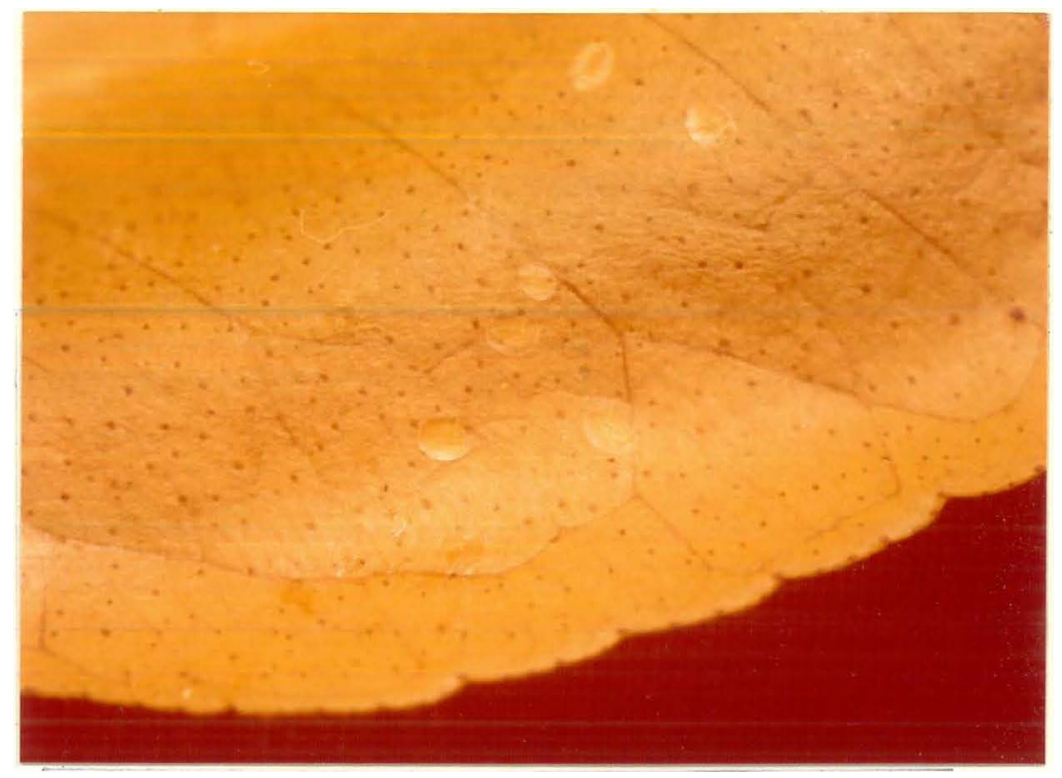

Fig. 3

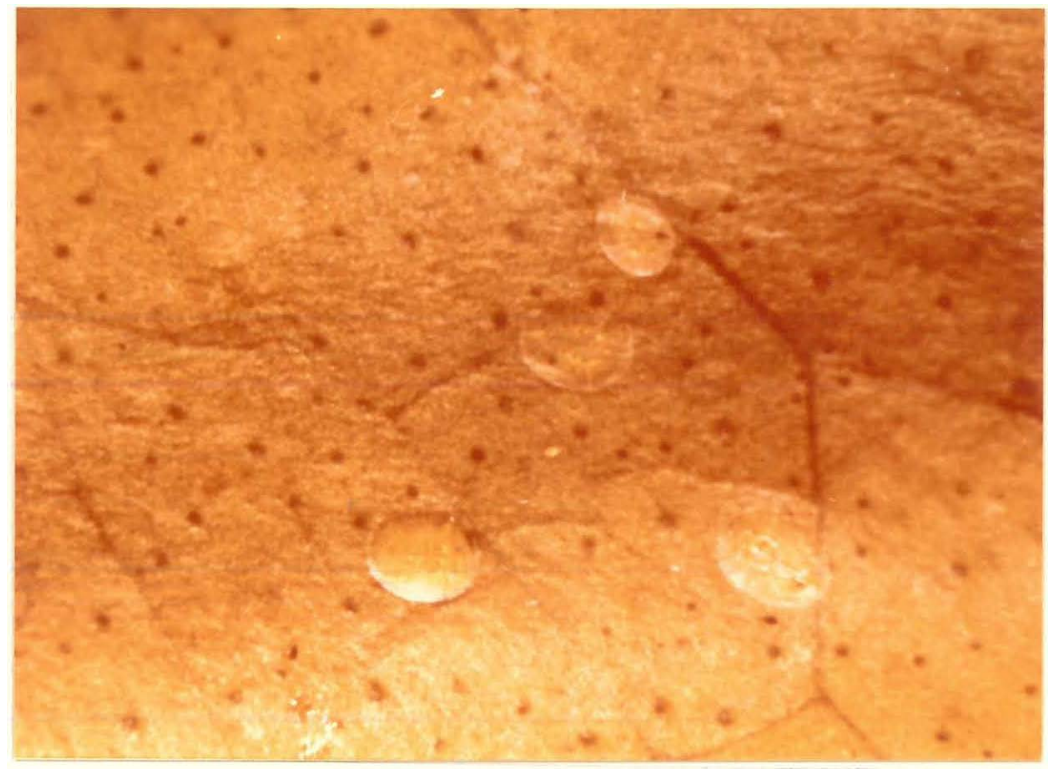

Fig. 4

Dialeurodes citrifolii (Morgan, 1893) sobre fothas de Citrus sp., fig. $3: 4 X$ e fig. $4: 8 X$ 


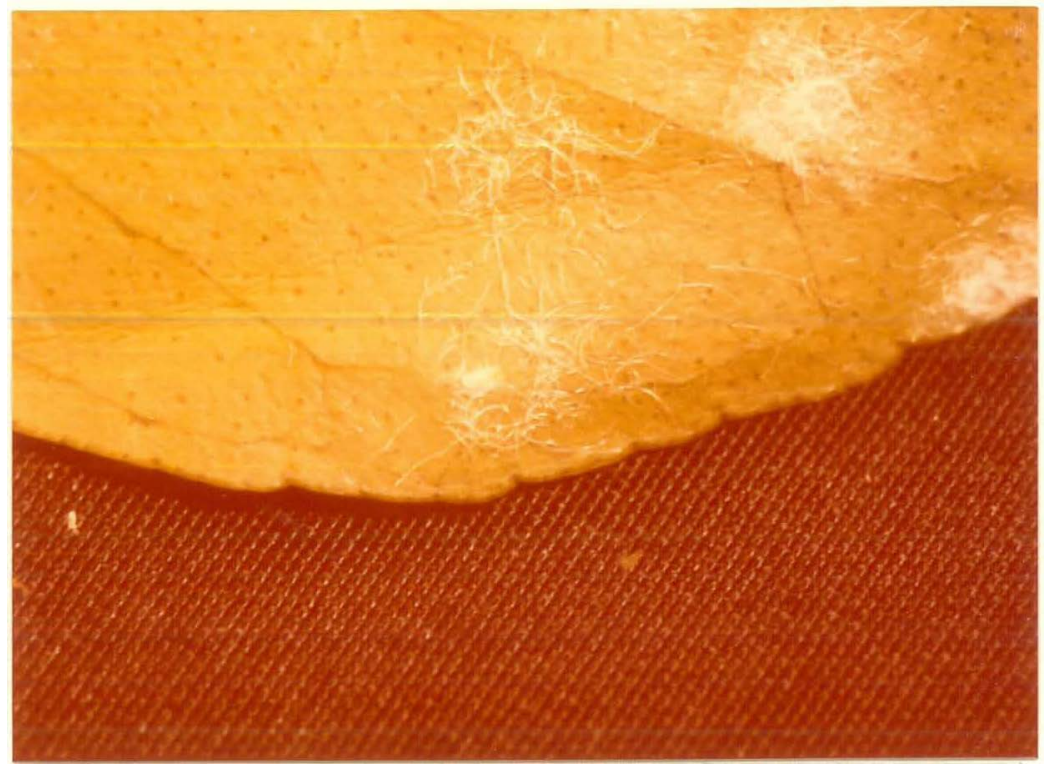

Fig. 5

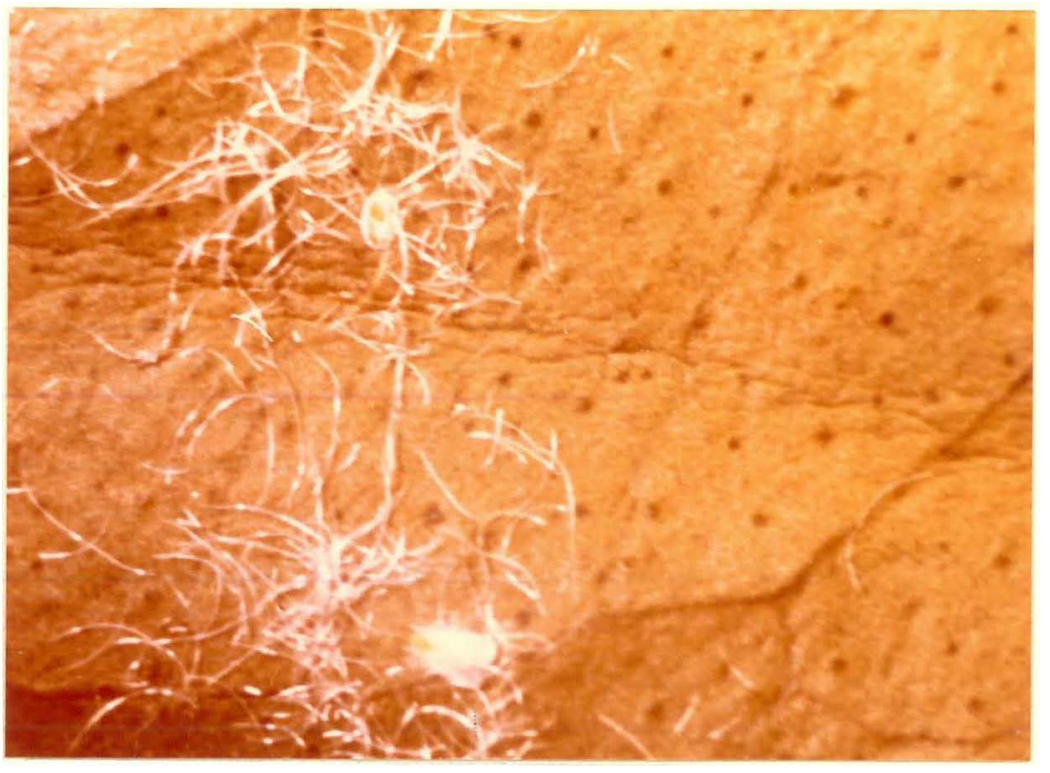

Fig. 6

Paraleyrodes bondari Peracchi, 1971 sobre fothas de Citrus sp., fig. $5: 4 X$ e fig. $6: 8 X$ 


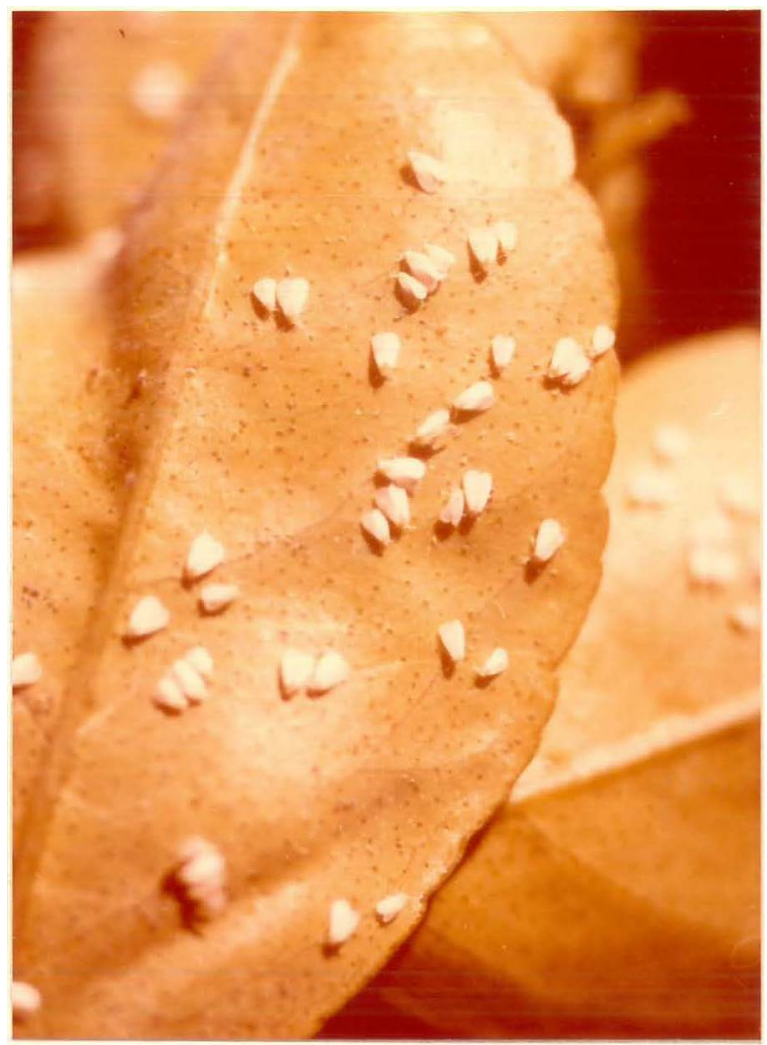

Fig. 7

Fig. 7. Aspecto de uma colônia de Dialeurodes citrifolii (Morgan, 1893), em limão taiti, Piracicaba-São Paulo. (2X) 


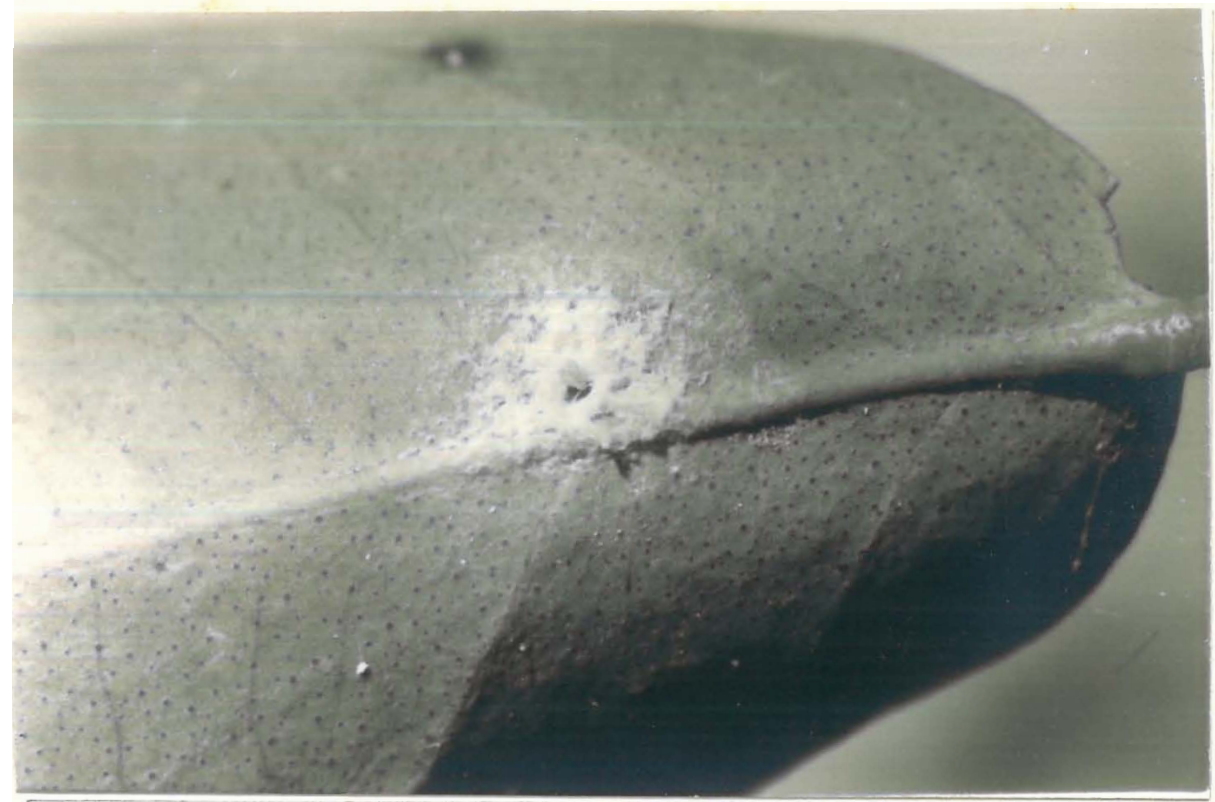

Fig. 8

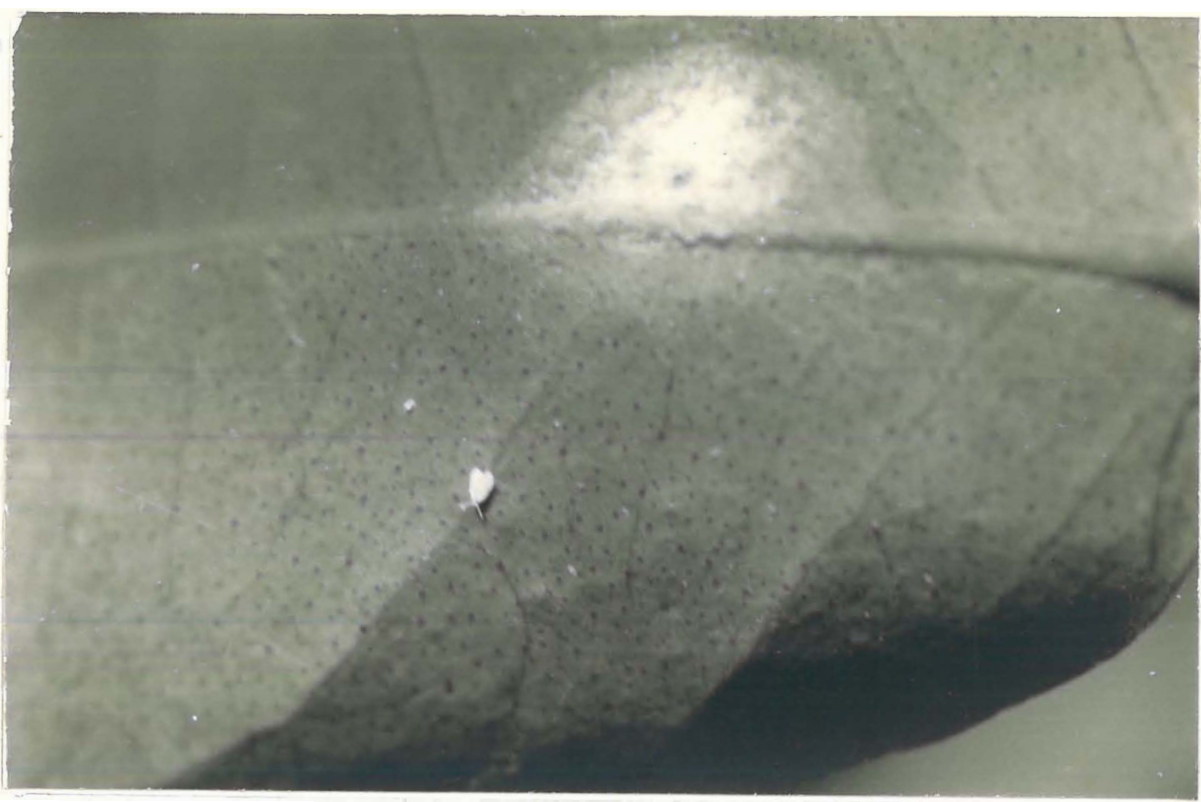

Fig. 9

Paralevrodes craleraformans Bondar, 1923 sobre fothas de Citmes sp., fig. 8: $4 X$ e fig. 9: $5 X$ 
AMOSTRA No

\begin{tabular}{|c|l|l|l|l|l|l|}
\hline$a ́ r v$. & $A_{0} f$. & D.c. & P. b. & & & Obs.: \\
\hline 1 & & & & & & \\
\hline 2 & & & & & & \\
\hline 3 & & & & & & \\
\hline 4 & & & & & & \\
\hline 5 & & & & & & \\
\hline 6 & & & & & & \\
\hline 7 & & & & & & \\
\hline 8 & & & & & & \\
\hline 9 & & & & & & \\
\hline 10 & & & & & & \\
\hline$T$ & & & & & & \\
\hline
\end{tabular}

Fig. 10. Ficha de campo, ulitizada para realizar as amostragens de aleirodídeos nos pomares citricolas visitados. A. f.: A. floccosus; D.c.: D. citrifolii e P.b.: $\underline{\text { P. bondari }}$ 


\begin{tabular}{|c|c|c|c|c|c|c|}
\hline $\begin{array}{l}\text { No da } \\
\text { cmost. }\end{array}$ & $\begin{array}{l}\text { Data } \\
\text { (1976) }\end{array}$ & $\begin{array}{l}\text { Município } \\
\text { visilado }\end{array}$ & $\begin{array}{l}\text { Na arv. } \\
\text { observ. }\end{array}$ & $\begin{array}{c}\text { No árv. } \\
\text { A. floccosus }\end{array}$ & $\begin{array}{l}\text { Noárv. } \\
\text { D. cilvifolli }\end{array}$ & $\begin{array}{l}\text { No rove } \\
\text { P. bonderi }\end{array}$ \\
\hline 01 & $5 / 05$ & Americana & 30 & 4 & 26 & 3 \\
\hline 02 & $6 / 01$ & Américo Bras iliense & 20 & 0 & 18 & 2 \\
\hline 03 & $15 / 05$ & Araraquara & 40 & 3 & 35 & 4 \\
\hline 04 & $15 / 05$ & Barretos & 60 & 5 & 53 & 4 \\
\hline 05 & $16 / 05$ & Bebcdouro & 50 & 2 & 38 & 3 \\
\hline 06 & $5 / 05$ & Campinas & 50 & 4 & 45 & 13 \\
\hline 07 & $14 / 04$ & Caçapava & 10 & 3 & 9 & 2 \\
\hline 08 & $29 / 05$ & Catanduva & 20 & 3 & 14 & 0 \\
\hline 09 & $15 / 05$ & Colina & 20 & 0 & 18 & 2 \\
\hline 10 & $16 / 05$ & Colombia & 30 & 0 & 25 & 3 \\
\hline 11 & $21 / 06$ & Cordeirópolis & 30 & 1 & 29 & 9 \\
\hline 12 & $14 / 04$ & Cruzeiro & 10 & 0 & 6 & 0 \\
\hline 13 & $15 / 05$ & Dobrada & 20 & 2 & 18 & 1 \\
\hline 14 & $6 / 04$ & Guará & 10 & 0 & 9 & 0 \\
\hline 15 & $6 / 04$ & Igarapava & 10 & 0 & $\cdot 8$ & $\hat{\imath}$ \\
\hline 16 & $17 / 05$ & Jaboticabal & 40 & 5 & 36 & 8 \\
\hline 17 & $28 / 04$ & Leme & 20 & 2 & 18 & 3 \\
\hline 18 & $28 / 04$ & Limeira & 60 & 0 & 58 & 9 \\
\hline 19 & $15 / 05$ & Matão & 40 & 0 & $37^{\circ}$ & 4 \\
\hline 20 & $28 / 04$ & Mogi-Mirim & 40 & 3 & 35 & 5 \\
\hline 21 & $30 / 05$ & Olimpia & 60 & 2 & 57 & 6 \\
\hline 22 & $6 / 04$ & Orlândia & 10 & 0 & 10 & 0 \\
\hline 23 & $24 / 04$ & Piracaia & 10 & 0 & 8 & 1 \\
\hline 24 & $21 / 05$ & Piracicaba & 60 & 1 & 51 & 12 \\
\hline 25 & $28 / 04$ & Piraçununga & 20 & 2 & 17 & 4 \\
\hline 26 & $15 / 05$ & Pilangueiras & 30 & 2 & 24 & 5 \\
\hline 27 & $6 / 01$ & Ribeirio Preto & 40 & 2 & 35 & 6 \\
\hline 28 & $29 / 05$ & Rio Claro & 20 & 2 & 17 & 0 \\
\hline 29 & $14 / 0.2$ & Roseira & 10 & 4 & 7 & 1 \\
\hline 30 & $6 / 01$ & Sales de Oliveira & 20 & 0 & 19 & 2 \\
\hline 31 & $6 / 01$ & São Carlos & 30 & 3 & 25 & 7 \\
\hline \multicolumn{3}{|c|}{ Total $: \ldots \ldots \ldots \ldots \ldots \ldots$} & 920 & 55 & 805 & $11 S$ \\
\hline
\end{tabular}

Tabela 1. Ocorrência de alcirodídeos em plantas círicas, verificada em algumas regióes livres para o plantio de Citrus no Estado de São Prulo. 


\begin{tabular}{|c|c|c|c|}
\hline \multirow{2}{*}{$\begin{array}{c}\text { No de árvores } \\
\text { observadas }\end{array}$} & \multicolumn{4}{|c|}{$N o$ de árvores com aleirodídeos (\%) } \\
\cline { 2 - 4 } & $\frac{A . \text { floccosus }}{D}$ & $\underline{\text { citrifolii }}$ & $\underline{\underline{P}}$ bondari \\
\hline 920 & $55(5,97 \%)$ & $805(87,50 \%)$ & $118(12,82 \%)$ \\
\hline
\end{tabular}

Tabela II. Percentagem de aleirodídeos nas plantas citricas observadas, em algumas regiões livres para o plantio de Citrus no Estado de São Paulo.

\begin{tabular}{|c|c|c|c|}
\hline \multirow{2}{*}{$\begin{array}{c}\text { Municípios } \\
\text { visitados }\end{array}$} & \multicolumn{3}{|c|}{ No de municipios com aleirodídeos (\%) } \\
\cline { 2 - 4 } & $\underline{\text { A. floccosus }}$ & $\underline{D} \cdot \underline{\text { citrifolii }}$ & $\underline{\underline{P}}$ bondari \\
\hline 31 & $20(64,51 \%)$ & $31(100 \%)$ & $25(80,82 \%)$ \\
\hline
\end{tabular}

Tabela III. Percentagem de municipios com aleirodídeos em algumas regiões livres para o plantio de Citrus no Estado de São Pau lo. 
11. PRANCHAS E MAPA 
Principais caracteres morfológicos de um aleirodídeo

A - Pupário

1 - tórax

2 - margem

3 - área submarginal

4 - poro composto

5 - disco dorsal

6 - abdome

7 - orifício vasiforme

8 - poro simples

B - Orifício vasiforme

9 - opérculo

10 - orifício

11 - língula 


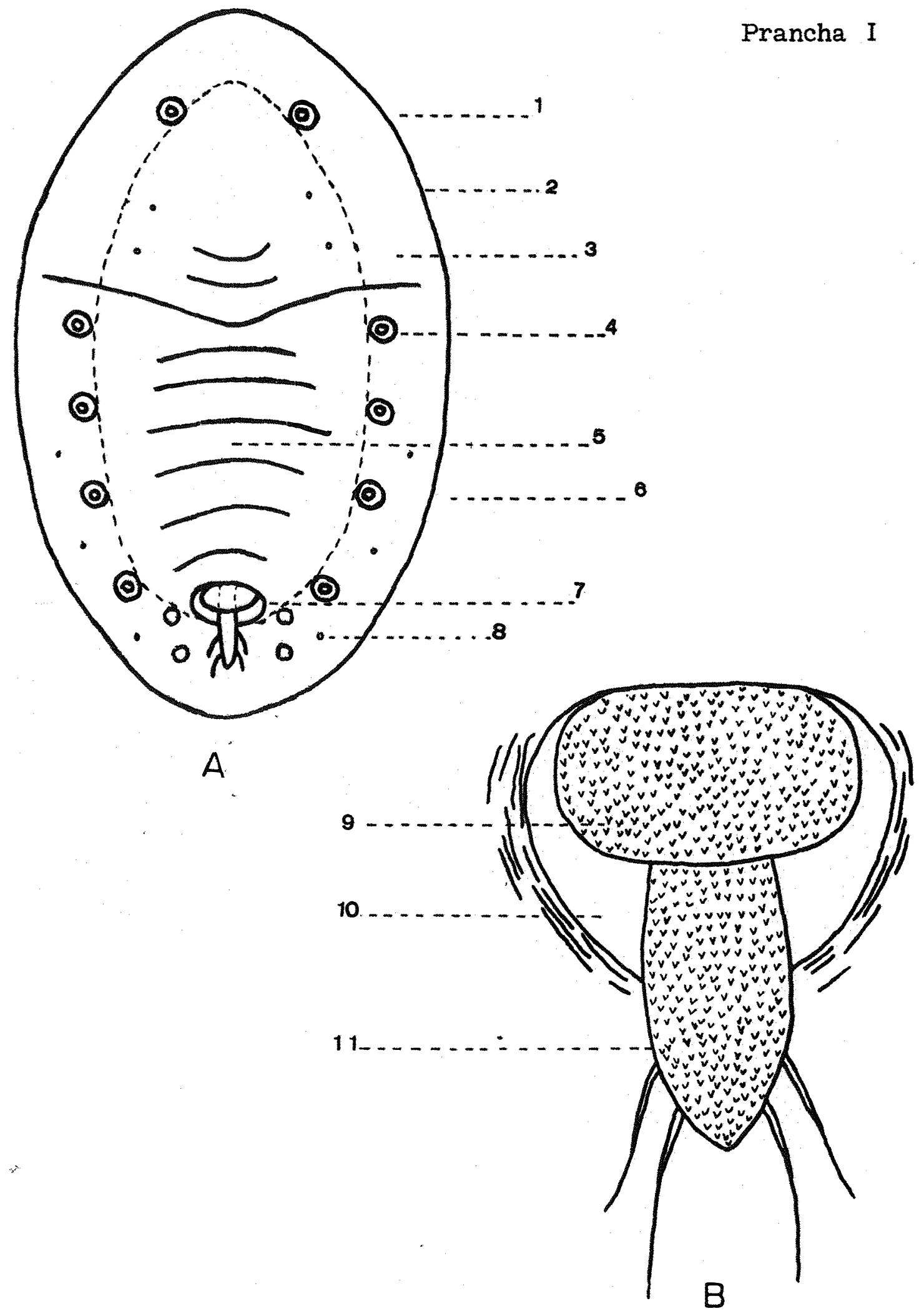



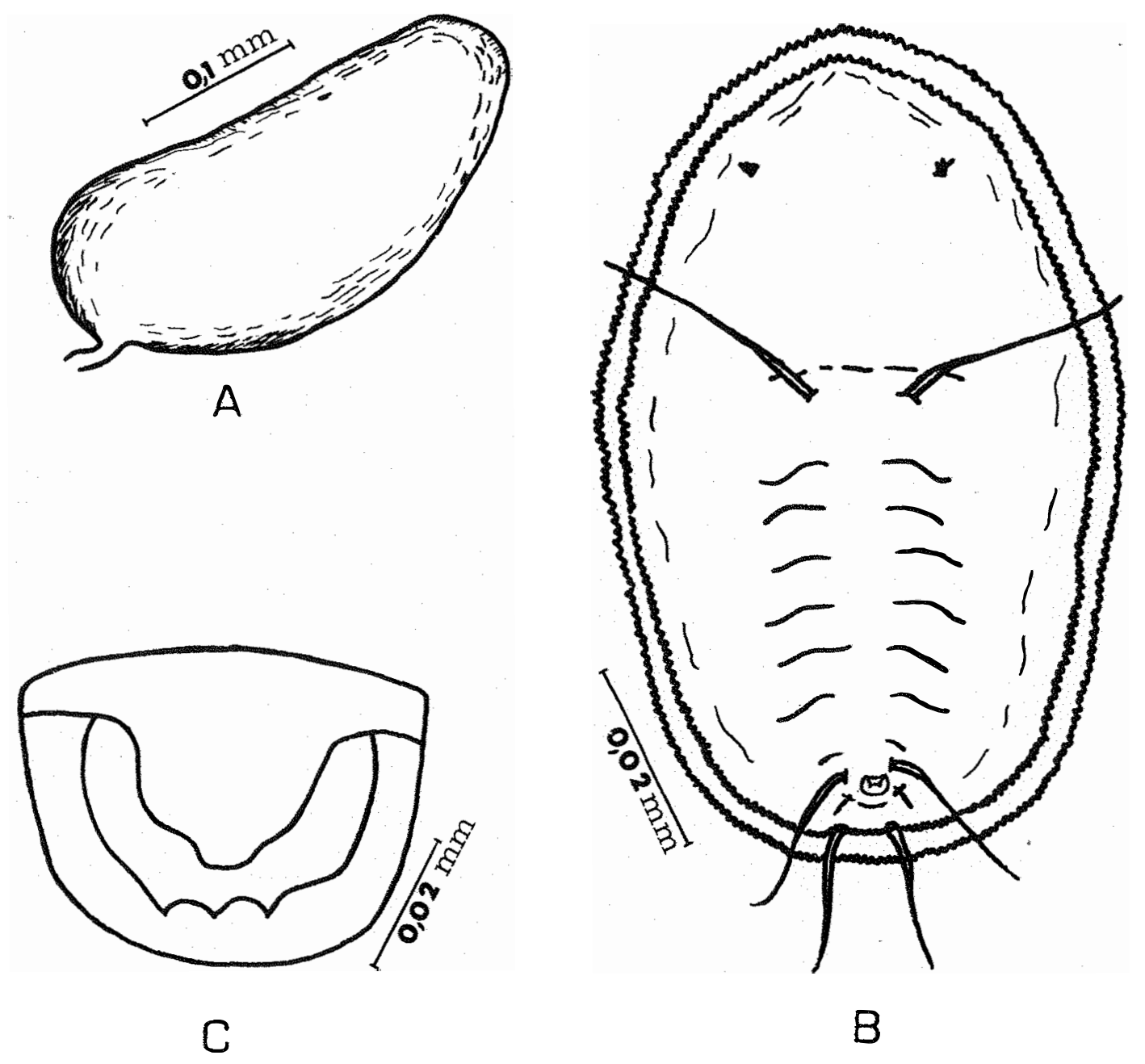

Aleurothrixus floccosus (Maskell, 1896)
A - ovo
B - pupário
C - orifício vasiforme 


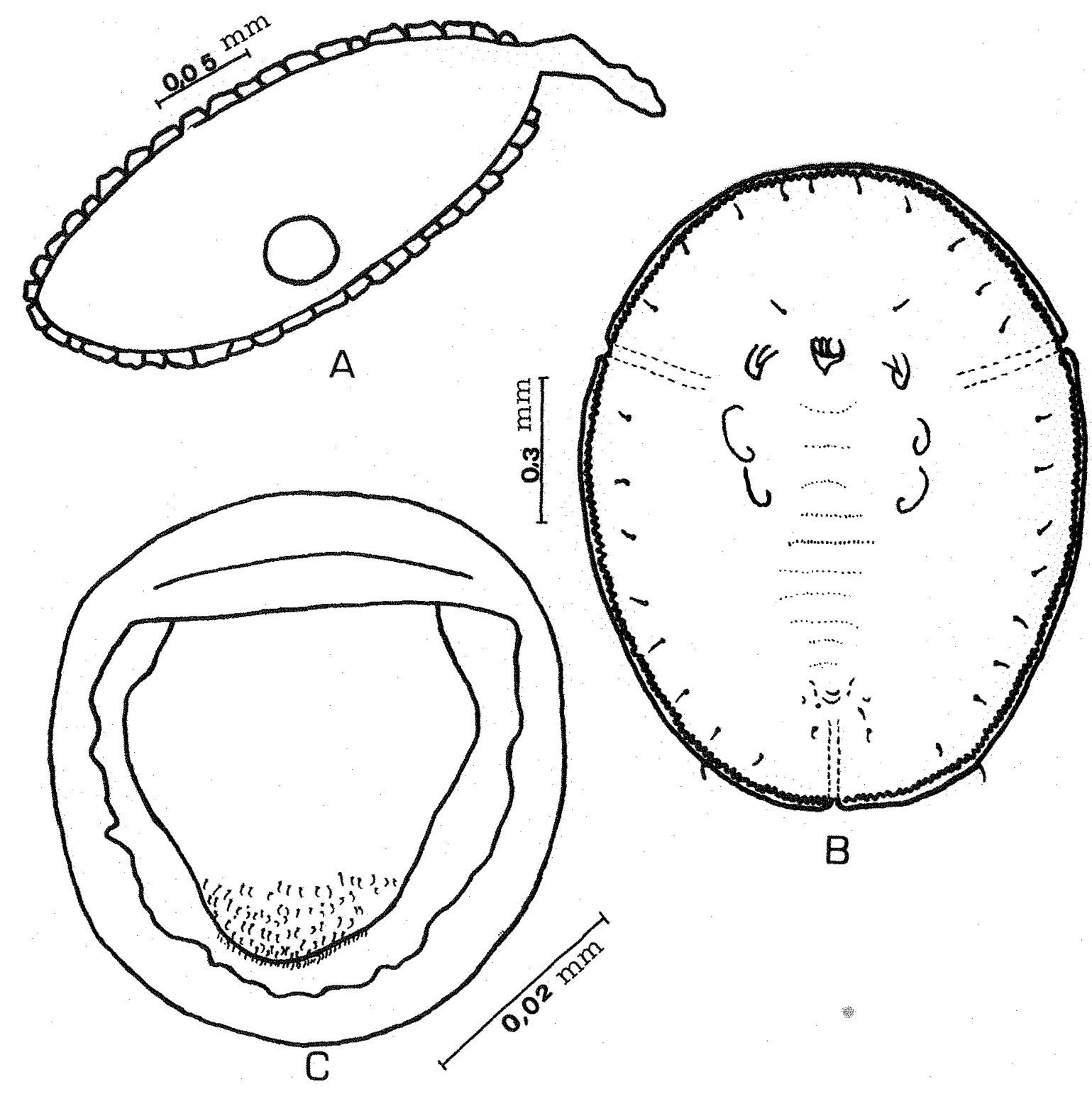

Dialeurodes citrifolii (Morgan, 1893)

$$
\begin{aligned}
& \text { A - ovo } \\
& \text { B - pupário } \\
& \text { C - orifício vasiforme }
\end{aligned}
$$




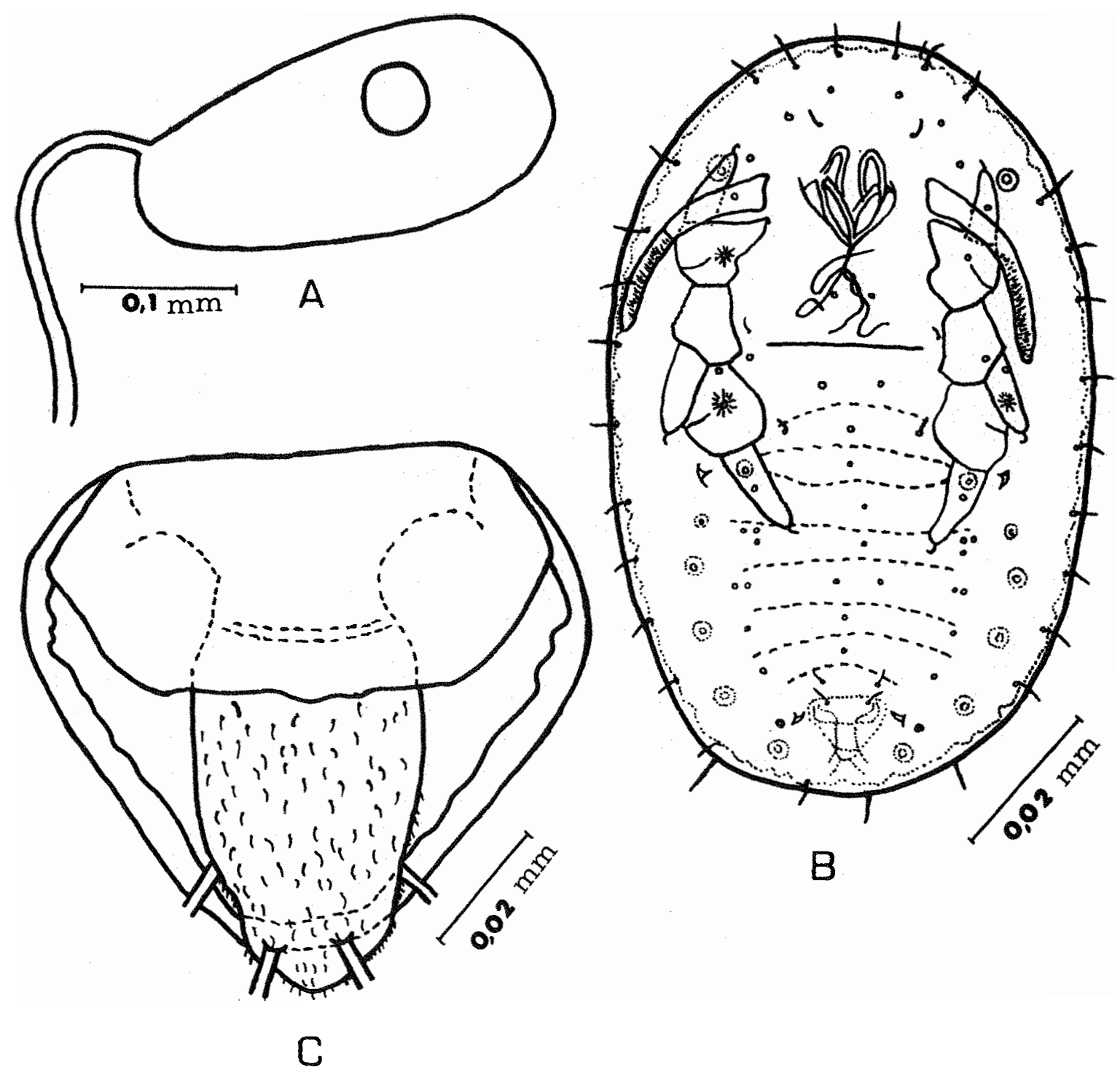

Paraleyrodes bondari Peracchi, 1971

$$
\begin{aligned}
& \text { A - ôvo } \\
& \text { B - pupário } \\
& \text { C - orifício vasiforme }
\end{aligned}
$$






